Jurnal Riset Agama

Volume 1, Nomor 3 (Desember 2021): 276-291

DOI: 10.15575/jra.v1i3.15593

https://journal.uinsgd.ac.id/index.php/jra

\title{
Nilai Sufistik Tarekat Idrisiyyah dalam Mengembangkan Karakter Santri
}

\author{
Muhamad Abdul Azis', Yulianti' ${ }^{2}$ Muhtar Gojali ${ }^{3}$ \\ 123Jurusan Tasawuf dan Psikoterapi, Fakultas Ushuluddin, \\ UIN Sunan Gunung Djati Bandung \\ muhamadabdulaziz102@gmail.com,yulianti@uinsgd.ac.id, \\ muhtargojali@uinsgd.ac.id
}

\begin{abstract}
This paper purpose is to determine how the concept of the value of Sufism in Idrisiyyah Islamic Boarding School Tasikmalaya. Second, how to apply the values of Sufism of the Idrisiyyah Tarekat in developing the character of the students of the Idrisiyyah Islamic Boarding School Tasikmalaya.this paper used qualitative method which data source from observation, interview, and literatures that related with the topic. The research result shows that Idrisiyyah as a religious institution engaged in an effort to develop the character of the students emphasizes on three religious pillars namely Faith, Islam, Ihsan, in the pattern of Sufism put forward Sufism amali oriented to Tazkiyyah annafsh (cleansing of the soul) tashfiyah al-qalb (building a positive character), and tahdzib al-akhlaq (building akhlakul karimah) trying to instill a positive character for the santri. One of the efforts to handle santri not be deceived by the world is with cultivation of sufistic values guided directly by Mursyid Tarekat Idrisiyyah namely Sheikh Akbar Muhammad Fathurrahman. Dhikr gives meaning to self-awareness which then encourages him consciously and with full responsibility to continue his dynamic life mission of giving meaning through righteous deeds.
\end{abstract}

Keywords: Character; Sufistic Value; Tarekat Idrisiyyah Tasikmalaya.

\begin{abstract}
Abstrak
Penelitian ini bertujuan untuk mengetahui bagaimana konsep nilai sufistik di Pondok Pesantren Idrisiyyah Tasikmalaya. Kedua bagaimana penerapan nilai sufistik Tarekat Idrisiyyah dalam mengembangkan karakter santri Pondok Pesantren Idrisiyyah Tasikmalaya. Dalam penelitian ini metode yang digunakan adalah metode kualitatif yang mana sumber data berasal dari hasil observasi dan wawancara serta literatur lainnya yang berkaitan dengan tema penelitian. Hasil penelitian
\end{abstract}


Jurnal Riset Agama, Volume 1, Nomor 3 (Desember 2021): 276-291

Muhamad Abdul Azis, Yulianti, Muhtar Gojali/Nilai Sufistik Tarekat Idrisiyyah dalam Mengembangkan Karakter Santri

ini menunjukkan bahwa Tarekat Idrisiyyah sebagai lembaga keagamaan yang bergerak di bidang tasawuf yang dalam upaya pengembangan karakter santrinya menitikberatkan pada tiga rukun agama yakni Iman, Islam, Ihsan, dalam corak tasawufnya mengedepankan tasawuf amali yang berorientasi kepada Tazkiyyah annafsh (pembersihan jiwa) tashfiyah al-qalb (membangun hati yang berkarakter positif), dan tahdzib al-akhlaq (membangun akhlakul karimah) berupaya menanamkan karakter positif bagi para santrinya. Salah satu upaya penanganan agar santri tidak terperdaya oleh dunia yaitu dengan penanaman nilai sufistik yang dibimbing langsung oleh Mursyid Tarekat Idrisiyyah yaitu Syeikh Akbar Muhammad Fathurrahman. Dzikir memberi makna kesadaran diri yang kemudian mendorong dirinya secara sadar dan penuh tanggung jawab untuk melanjutkan misi hidupnya yang dinamis memberi makna melalui amal-amal shaleh.

Kata kunci: Karakter; Nilai Sufistik; Tarekat Idrisiyyah Tasikmalaya.

\section{Pendahuluan}

Santri merupakan seseorang yang sedang mendalami agama dan menetap di pesantren. Walaupun santri merupakan seseorang yang mendalami ilmu agama, tidak dapat dipungkiri terdapat sebagian santri yang kurang mencermati aturan-aturan yang telah dibuat pondok yang sebenarnya tugas santri yakni tinggal melaksanakan serta mentaati peraturan yang telah dibuat dari pondok serta tidak melanggar ketentuan yang telah ditetapkan. Dilansir dari jawapos.com pada tanggal 9 juli 2020 "kabur dari ponpes, seorang santri tewas," dalam berita tersebut santri meninggalkan pesantren tanpa pamit dan ditemukan tewas di pinggir jalan (Cahyono, 2019). Dari berita tersebut dapat dikatakan terjadinya disorientasi, hampir tidak adanya perpaduan antara hidup dengan spiritual religious, hilangnya orientasi akhirat. Faktor yang membuat santri tidak betah di pesantren salah satunya dalam proses adaptasi. Dalam proses pendidikan, Idrisiyyah memberikan asupan-asupan spiritual untuk membantu santri menemukan makna kehidupan. Asupan spiritual yang diberikan salah satunya melalui dzikir makhsus dilaksanakan setiap malam jum'at di bawah bimbingan Syekh Akbar Muhammad Fathurrahman sehingga santri dapat menemukan makna kehidupan sehingga menjadikan santri sebagai individu lebih yang baik.

Dimensi spiritual adalah elemen yang cukup penting dalam membentuk karakter dan pribadi seseorang manusia. Begitu juga dalam membentuk keimanan dan ketakwaan dalam diri seseorang individu, 
Jurnal Riset Agama, Volume 1, Nomor 3 (Desember 2021): 276-291

Muhamad Abdul Azis, Yulianti, Muhtar Gojali/Nilai Sufistik Tarekat Idrisiyyah dalam Mengembangkan Karakter Santri

aspek spiritual adalah sangat penting. Dengan demikian, dilihat besarnya keperluan untuk sentiasa menjaga dan memelihara aspek rohani atau spiritual seseorang individu dalam upaya untuk memastikan akhlak dan moral insan senantiasa berada dalam keadaan yang positif, seterusnya mampu menatijahkan kepribadian yang sejahtera (Wan Saleha Wan Sayed, 2020, p. 66).

Peningkatan kualitas santri yang harus diperhatikan bukan hanya sekedar unsur jasmani dan akal semata, seperti yang telah dijelaskan dalam Al-Quran ada lima unsur dalam diri manusia yaitu jasad, akal, hati, jiwa dan ruh. Kelima unsur ini memiliki perannya masing-masing namun hendaknya sejalan menyatu dalam satu kesatuan yang utuh. Sehingga menciptakan manusia baik secara jasadi, akal, hati jiwa dan ruh secara kualitas meningkat beriringan yang berdampak bagi kemanfaatan untuk dirinya dan sesama.

Dalam implementasinya, Pondok Pesantren Tarekat Idrisiyyah melaksanakan amaliyah Tarekat, secara garis besar sama dengan amalan lainnya. Adapun kemudian, bahwa awrad ini disusun dan diatur oleh Guru, Pelindung ruhani dan Pembimbing Tarekat Idisiyyah Syekh Muhammad Fathurahman yang wajib diamalkan bagi segenap kaum muslimin muslimat yang berminat, khususnya jamaah tarekat Idrisiyyah itu sendiri.

Beberapa karya terdahulu yang telah membahas tentang nilai sufsitik yaitu Skripsi berjudul Nilai-Nilai Sufistik dalam Karya-karya Emha Ainun Najib ditulis oleh mahasiswa Fakultas Ushuluddin IAIN Raden Intan Lampung yang bernama Rusmaini. Skripsi dengan pendekatan filosofos ini menjelaskan hubungan manusia dengan manusia, hubungan manusia dengan Tuhan, hubungan manusia dengan alam, dimana ketiganya tidak dapat dipisahkan (Rusmaini, 1999, p. 56). Kedua, Skripsi berjudul Aplikasi Nilai-nilai Sufistik terhadap Mahasiswa Tasawuf Psikoterapi dalam Kehidupan Modern. Artikel ini mencoba menjelaskan bagaimana tasawuf yang benar, walaupun secara sistematis mahasiswa tasawuf psikoterapi sudah mempelajari konsep tasawuf itu sendiri. Jika nilai-nilai sufistik diaplikasikan secara benar, maka mahasiswa Tasawuf psikoterapi akan memiliki kehidupan yang tenang serta menjauh dari hal-hal yang berbau penyimpangan sosial seperti minum minuman keras, konsumsi obat terlarang dan pergaulan bebas (Muhammad Baidhawi, 2016, p. 85). Ketiga, buku berjudul Sufisme dan Pengembangan Pendidikan Karakter. Dalam buku karya H. Subaidi, dijelaskan bagaimana manusia memperoleh ilmu pengetahuan serta kegunaannya agar senantiasa meningkatkan kesadaran illahiah (DR. H. Subaidi, 2015, p. 252).

Penelitian ini berbeda dengan karya-karya yang telah disebutkan di atas. Peneliti mencoba menggali lebih dalam tentang nilai sufistik tarekat Idrisiyyah dalam mengembangkan karakter santri. 
Jurnal Riset Agama, Volume 1, Nomor 3 (Desember 2021): 276-291

Muhamad Abdul Azis, Yulianti, Muhtar Gojali/Nilai Sufistik Tarekat Idrisiyyah dalam Mengembangkan Karakter Santri

Karakter merupakan bagian utama dalam diri manusia, karakter juga dapat diartikan sebagai kepribadian. Kepribadian sebagai ciri khas diri manusia yang terbentuk melalui lingkungan. Dalam bahasa Yunani karakter atau carrasein berarti membuat corak yang konsisten dan tidak hilang (Zubaedi, 2012, p. 12).

Dalam istilah Islam karakter dikenal dengan sebutan akhlak. Oleh karena itu karakter Islami harus berasaskan pada nilai-nilai pengetahuan illahiah, bermuara dari nilai-nilai kemanusiaan dan berlandaskan pada ilmu pengetahuan. Pembentukan karakter diawali dengan pengetahuan atau teori, pengetahuan tersebut bisa bersumber dari pengetahuan agama, sosial dan budaya (Pupuh Fathurrohman, 2013, p. 15). Akhlak tidak lepas kaitannya dengan tasawuf, sebab tasawuf berbicara akhlak manusia dengan Tuhannya, akhlak manusia dengan sesamanya. Lahirnya agama Islam berarti lahirnya ajaran akhlak dalam islam, sebagaimana misi utama Rasulullah diutus ke dunia yaitu untuk memperbaiki akhlak manusia.

Menurut Zakariah al-Anshari Tasawuf merupakan ilmu tentang kebersihan jiwa, perbaikan budi perketi, serta pembangunan lahir dan batin guna memperoleh kebahagian abadi (Nasaruddin, 2014, p. 2). Tasawuf bukan sekedar ilmu, teori atau sekedar kontemplasi spekulatif semata melainkan sebuah sari pengalaman yang menggabungkan pemikiran, perilaku dan perasaan serta merefleksikan hakikat manusia secara utuh tatkala menemukan tujuannya. Oleh karena itu sumber-sumber filosofis dan non- filosofis dapat ditemukan dalam dunia tasawuf. Namun dengan hanya mengandalkan faktor ini untuk kemudian menarik kesimpulan general, akan mengaburkan hakekat tasawuf dan menyalahi obyektifitas pengkajian ilmiah. Yang hendak ditekankan adalah bahwa perlu memandang tasawuf lebih terbuka dan ada 'kesiapan' memandang lingkupnya yang ril yang tidak terbatas pada pemikiran saja atau perilaku saja atau bahkan perasaan saja secara terpisah (Kamba, 2013, p. 66).

Ilmu tasawuf perlu dimasyarakatkan, karena dilihat dari perubahan zaman yang semakin canggih dan semakin milenial tentu banyak sekali sifat-sifat yang jauh dari nilai-nilai Islam baik dalam perbuatannya maupun perkataan dan tindakannya. Karena dengan munculnya sifat-sifat yang jauh dari nilai-nilai keislaman itu banyak menimbulkan hal negatif dalam kehidupan, misalnya saja menjadikan manusia jadi lebih mementingkan dunia dan melupakan akhirat. Bahkan bisa mengakibatkan dampak yang lebih negative lagi baik bagi dirinya atau keluarga, masyarakat dan negara. Karena jika tiang dan pondasi agama sudah rusak atau dalam artian nilai tasawuf sudah tidak dihiraukan lagi maka kehidupan pun akan porak poranda.

Nilai tasawuf harus dikenalkan kepada masyarakat luas, sebagaimana Komarudin Hidayat berpendapat bahwa ada tiga bagian mengapa tasawuf harus dimasyarakatkan, di antaranya Tasawuf atau kehidupan sufi 
Jurnal Riset Agama, Volume 1, Nomor 3 (Desember 2021): 276-291

Muhamad Abdul Azis, Yulianti, Muhtar Gojali/Nilai Sufistik Tarekat Idrisiyyah dalam Mengembangkan Karakter Santri

memiliki peran penting dalam mengarahkan manusia dari kebimbangan akibat terkikisnya nilai-nilai spiritual agama. Kedua, memunculkan sumbersumber esoteric (kebatinan) Islam. Ketiga, menegaskan akan pentingnya aspek esoteric silam sebagai inti atau jantung ajaran agama Islam (Junaidin, 2019, p. 28).

Dari uraian di atas, penulis mengambil rumusan masalah untuk membatasi masalah menjadi dua pertanyaan. Pertama, bagaimana konsep nilai sufistik Tarekat Idrisiyyah di Pondok Pesantren Idrisiyyah Tasikmalaya? Kedua, bagaimana penerapan nilai sufistik Tarekat Idrisiyyah dalam mengembangkan karakter santri Pondok Pesantren Idrisiyyah Tasikmalaya?

Sesuai dengan grand teori yang diangkat dalam rumusan masalah, maka penelitian ini bertujuan untuk mengetahui konsep nilai sufistik tarekat Idrisiyyah Pondok Pesantren Idrisiyyah Tasikmalaya. Kedua, untuk mengetahui penerapan nilai sufistik Tarekat Idrisiyyah dalam mengembangkan karakter santri Pondok Pesantren Idrisiyyah Tasikmalaya. Penelitian ini diharapkan dapat berkontribusi dalam ekspansi keilmuan, terutama untuk Jurusan Tasawuf Psikoterapi. Kedua, penelitian ini diharapkan mampu memotivasi pondok pesantren lainnya dalam mengembangkan karakter santri.

\section{Metode Penelitian}

Metode penelitian merupakan teknik untuk mencapai tujuan dari penelitian, sehingga rumusan masalah yang ada dapat terjawab dengan tepat secara ilmiah (Syamsuddin, 2007, p. 71). Pendekatan yang digunakan dalam peniliti adalah metode kualitatif. Penelitian kualitatif yaitu pandangan dari orang yang berperan langsung pada suatu kegiatan dengan rencana yang bersifat dapat menyesuaikan dan saling aktif. Juga diarahkan untuk mengetahui fakta-fakta sosial dari pandangan partisipan dan dipakai untuk meneliti suatu keadaan objek yang alamiah (Kependidikan, 2008, p. 22). Adapun metode yang digunakan adalah deskriptif dengan jenis studi kasus di Pondok Pesantren Idrisiyyah Tasikmalaya. Sumber data yang peneliti ambil dalam penelitian ini adalah data primer dan data sekunder. Sumber data primer, diperoleh dari wawancara pada Ketua Lembaga Sufi Training Center, Ketua Majelis Ketarekatan Idrisiyyah, Kepala Direktorat Ma'had Aly Idrisiyyah, Pengajar di Pondok Pesantren Tarekat Idrisiyyah dan Santri di Pondok Pesantren Tarekat Idrisiyyah. Sedangkan sumber data sekunder, diperoleh dari jurnal, skripsi, artikel, dan buku-buku yang berkesinambungan dengan nilai sufistik dan karakter.

Pada penelitian ini, peneliti mengumpulkan data untuk bahan tulisannya dengan menggunakan metode observasi, wawancara, dan dokumentasi. Pertama, observasi adalah peneliti secara langsung 
Jurnal Riset Agama, Volume 1, Nomor 3 (Desember 2021): 276-291

Muhamad Abdul Azis, Yulianti, Muhtar Gojali/Nilai Sufistik Tarekat Idrisiyyah dalam Mengembangkan Karakter Santri

mengunjungi lokasi penelitian dengan cara mengamati secara langsung guna mendapatkan sebuah data (Moleong, 2009, p. 32) Kedua, wawancara merupakan tahapan untuk mendapatkan informasi yang dilakukan dengan cara tanya jawab dengan cara bertatap muka antara pewawancara dengan informan atau orang yang diwawancarai, dengan melibatkan kehidupan sosial yang sudah ada sejak lama. Ketiga, dokumentasi adalah proses pengumpulan data untuk membuktikan hasil penelitian yang sedang atau telah dilaksanakan yaitu berupa foto, gambar, tulisan dan lain-lain. Dokumen berbentuk tulisan seperti cerita, biografi, catatan harian. Sedangkan dokumen berbentuk gambar bisa berupa foto-foto (Sukmadinata, 2009, p. 54). Dokumentasi merupakan pelengkap dari wawancara dan observasi itu sendiri.

\section{Hasil dan Pembahasan}

\section{Konsep Nilai Sufistik Tarekat Idrisiyyah}

Tasawuf adalah proses pembersihan diri menuju yang lebih baik dan orang yang menjalankan itu disebut sufi (Bagir H. , 2019, p. 52). Istilah pembersihan hati (Tazkiyatun Nafs) menurut sebagian ulama dibagi menjadi tiga yaitu: pertama, Takhalli berarti meninggalkan hal-hal atau sikap-sikap rendah, sikap-sikap yang tidak terpuji. Kedua, Tahalli berarti menghiasi dengan hal-hal yang baik. Ketiga, Tajalli berarti terbuka antara manusia dengan Allah sehingga dapat mecapai maqam marifat. Menurut Robert Frager, Tasawuf merupakan sebuah pendakian atau pendekatan yang sangat holistic-mengintegrasikan fisik, psikis, dan spiritual (Gojali, 2019, p. 6).

Tasawuf tidak hanya sekedar lahir, tapi tasawuf lebih pada batin. AlGhazali memberikan penjelasan singkat tentang pokok-pokok tasaswuf yaitu Hablum minallah yang berarti istiqomah bersama Allah dan Hablum minannas berarti harmonis dengan sesama makhluk meliputi manusia, lingkungan dan apa yang ada di sekelilingnya. Teori yang dijelaskan oleh al-Ghazalai sesuai dengan yang diwariskan oleh Nabi Muhammad tentang tiga aspek yang harus dilakukan manusia terutama bagi umat muslim yaitu Iman, Islam, Ihsan. Tiga aspek tersebut bersifat penyerahan diri kepada Allah, ketiga aspek tersebut memiliki kesatuan dan keseimbangan yang tidak dapat dipisahkan. Tasawuf menjadi salah satu kunci agar kita sebagai manusia bisa memilih mana yang lebih baik dan yang sesuai nilai-nilai Islam dalam melakukan segala hal (Kamba, 2018, p. 26). 
Jurnal Riset Agama, Volume 1, Nomor 3 (Desember 2021): 276-291

Muhamad Abdul Azis, Yulianti, Muhtar Gojali/Nilai Sufistik Tarekat Idrisiyyah dalam Mengembangkan Karakter Santri

Tabel 1. Objek Kajian

\begin{tabular}{|c|c|c|c|c|}
\hline No & Pondasi & Ilmu & Objek & Fungsi \\
\hline 1 & Iman & Aqidah & Allah & $\begin{array}{l}\text { Menyembah } \\
\text { kepada Allah }\end{array}$ \\
\hline 2 & Islam & Fiqih & $\begin{array}{l}\text { Aturan- } \\
\text { aturan Allah }\end{array}$ & $\begin{array}{l}\text { Mengatur } \\
\text { kehidupan } \\
\text { dengan aturan- } \\
\text { aturan Allah }\end{array}$ \\
\hline 3 & Ihsan & Tasawuf & Hati/Qalb & $\begin{array}{l}\text { Spiritual } \\
\text { membahas } \\
\text { ibadah hati } \\
\text { yang telah } \\
\text { diolah }\end{array}$ \\
\hline
\end{tabular}

Di kalangan orang awam memahami tasawuf sebagai ilmu yang harus dipelajari dan dipraktekan di saat umur mencapai 40 tahun padahal dalam tiga dasar rukun agama tasawuf menjadi hal penting yang harus diterapkan sedini mungkin.

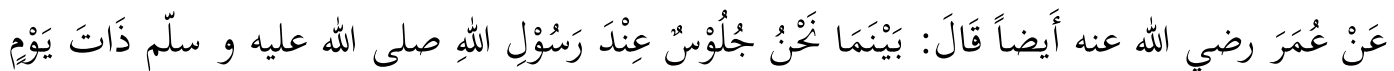

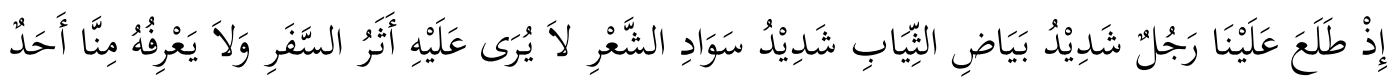

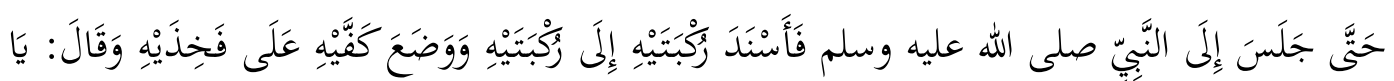

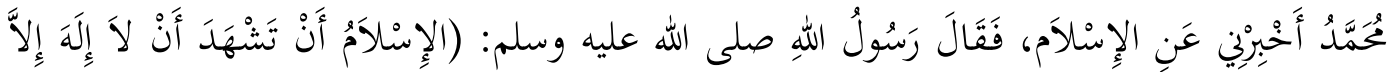

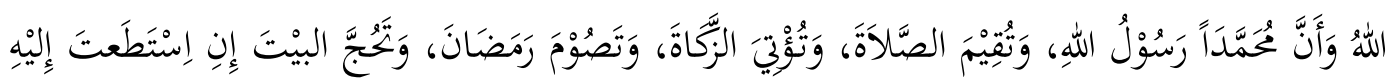

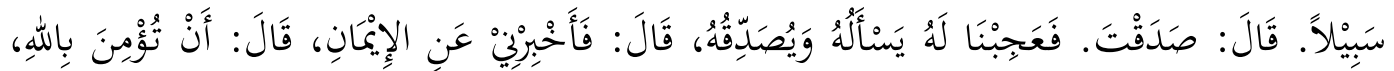

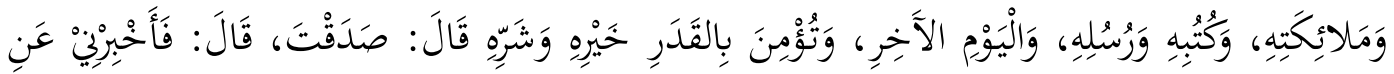

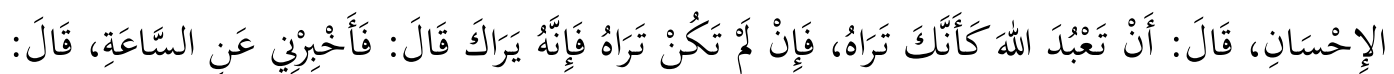

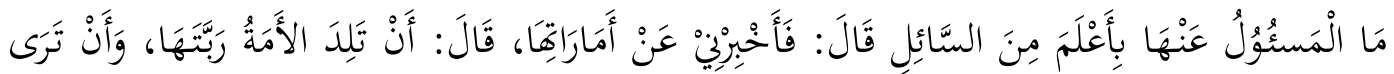

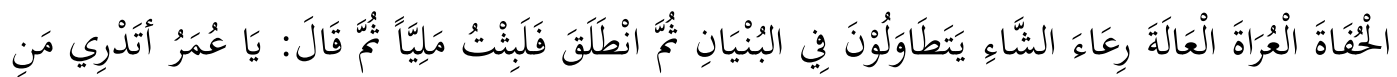

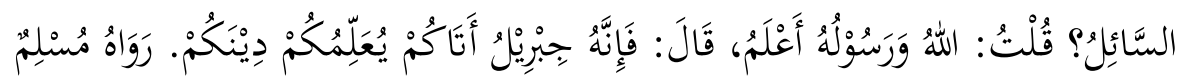

Artinya: "Dari Umar radhiyallahu 'anhu pula dia berkata; pada saat kami duduk lalu datang seseorang menggunakan kain berwarna putih, rambutnya sangat hitam dan tidak ada tanda-tanda bekas perjalanan. Lalu ia menanyakan tentang iman, Islam, Ihsan Nabi 
Jurnal Riset Agama, Volume 1, Nomor 3 (Desember 2021): 276-291

Muhamad Abdul Azis, Yulianti, Muhtar Gojali/Nilai Sufistik Tarekat Idrisiyyah dalam Mengembangkan Karakter Santri

shallallahu 'alaihi wa sallam menjawab: "Islam itu adalah engkau bersaksi bahwa tidak ada sesembahan yang berhak diibadahi dengan benar kecuali Allah dan Muhammad adalah utusan-Nya, engkau menegakkan shalat, menunaikan zakat, puasa Ramadhan dan haji ke Baitullah Al-Haram jika engkau mampu mengadakan perjalanan ke sana." Laki-laki tersebut berkata: 'Engkau benar.' Maka kami pun terheran-heran padanya, dia yang bertanya dan dia sendiri yang membenarkan jawabannya. Dia berkata lagi: "Jelaskan kepadaku tentang iman?" Nabi shallallahu 'alaihi wa sallam menjawab: "(Iman itu adalah) Engkau beriman kepada Allah, malaikat-malaikat-Nya, kitab-kitab-Nya, rasul-rasul-Nya dan hari akhir serta engkau beriman kepada takdir baik dan buruk." Ia berkata: 'Engkau benar.' Kemudian laki-laki tersebut bertanya lagi: 'Jelaskan kepadaku tentang ihsan?' Beliau shallallahu 'alaihi wa sallam bersabda: "(Ihsan adalah) Engkau beribadah kepada Allah seolah-olah engkau melihat-Nya. Kalaupun engkau tidak bisa melihat-Nya, sungguh Diamelihatmu." Dia berkata: "Beritahu kepadaku kapan terjadinya kiamat?" Nabi shallallahu 'alaihi wa sallam menjawab: "Tidaklah orang yang ditanya lebih mengetahui dari yang bertanya." Ia berkata: "Jelaskan kepadaku tanda-tandanya!" Nabi shallallahu 'alaihi wa sallam berkata: "Jika seorang budak wanita melahirkan tuannya dan jika engkau mendapati penggembala kambing yang tidak beralas kaki dan tidak pakaian saling berlomba dalam meninggikan bangunan." Umar radhiyallahu 'anhu berkata: 'Kemudian laki-laki itu pergi, aku pun terdiam sejenak.' Maka Rasulullah shallallahu 'alaihi wa sallam bertanya kepadaku: "Wahai 'Umar, tahukah engkau siapa orang tadi?" Aku pun menjawab: "Allah dan Rasul-Nya lebih tahu." Nabi shallallahu 'alaihi wa sallam bersabda: "Dia adalah Jibril yang datang untuk mengajarkan agama ini kepada kalian" (HR.Muslim).

Pada zaman Rasulullah tidak ada penamaan tasawuf. Nama tasawuf muncul ketika diformulasikan oleh para tabiin yang sumbernya dari ihsan. Dimana iman menjadi ilmu aqidah, Islam menjadi Ilmu fiqih dan ihsan menjadi tasawuf (Fauzi, 2021, p. 14.23 WIB).

Ilmu tasawuf sebagai ilmu untuk mengetahui kondisi hati manusia. Ilmu tasawuf akan dapat mendeteksi kondisi hati manusia apakah madmumah (buruk) karena ada penyakit dalam hatinya atau mahmud (terpuji) karena memiliki kesabaran, tawakal, ridho. Tasawuf dalam kajian amaliah sesuai apa yang diajar oleh Nabi Muhammad Saw kepada para sahabat adalah konsentrasi pada wilayah hati, selalu menjaga hati, membersihkan hati sehingga terbit mata hati orang-orang yang memngamalkan tasawuf. Tasawuf menghadirkan akhlak mulia yang universal yang tidak luntur oleh waktu dan tidak lekang oleh zaman. 
Jurnal Riset Agama, Volume 1, Nomor 3 (Desember 2021): 276-291

Muhamad Abdul Azis, Yulianti, Muhtar Gojali/Nilai Sufistik Tarekat Idrisiyyah dalam Mengembangkan Karakter Santri

Tasawuf juga disebut kesucian hati, sehingga dengan kesucian hati manusia dapat menjadi pribadi yang seutuhnya, dalam artian menjadi manusia yang memiliki akhlak mulia. Para ulama membagi tasawuf dibagi menjadi tiga, pertama tasawuf amali, tasawuf akhlaki, tasawuf falsafi. Tasawuf amali adalah tasawuf yang diamalkan. Ada beberapa istilah dalam tasawuf amali yaitu;

a) Tarekat, adalah jalan yang harus ditempuh oleh seorang sufi, dengan tujuan untuk berada sedekat mungkin dengan Allah.

b) Mursyid, adalah pembimbing. Mursyid dianggap memiliki mata batin sehingga mursyid sebagai pembimbing memberikan amalan sesuai dengan kemampuan murid.

c) Murid, adalah orang yang berkehendak menuntut ilmu, yang mau dibimbing oleh mursyid. Murid dibagi menjadi tiga tingkatan, pertama mubtadi yang artinya sebagai murid pemula, pada tingkatan ini mursyid memberikan amalan-amalan dasar saja seperti shalat lima waktu, membaca Al-Quran. Tingkatan kedua adalah mutawassith berasal dari kata wassith yang berarti tengah dimana pada tingkatan ini murid diberi amalan lebih tinggi dari murid pemula seperti tambahan dzikir, amalan-amalan sunnah yang mengikuti salat wajib yang kita kenal dengan rawatib. Tingkatan ketiga yaitu mumtahi berasal dari kata imtaha yang berarti lebih tinggi. Pada tingkatan ini murid sudah matang ilmu syariatnya, ilmu tauhidnya baru ilmu tasawuf, sebab jika tidak matang ilmu fiqih dan tauhidnya maka belajar tasawuf akan membuat gila,akan saling menyesatkan.

d) Suluk, yaitu menempuh jalan menuju Allah, orang yang menempuh jalan tersebut disebut salik. Banyak aktifitas yang dilakukan orang yang memilih jalan suluk salahsatunya adalah uzlah. Uzlah artinya menyendiri, tidak mau dengan hingar bingar duniawi (Fauzi, 2021, p. 14.23).

Ajaran-ajaran dalam tarekat dapat dibedakan menjadi dua: yaitu ada yang bersifat khusus dan ada yang bersifat umum. Pertama, ajaran yang bersifat khusus, yaitu amalan yang harus benar-benar dilaksanakan pengikut sebuah tarekat, dan tidak boleh diamalkan orang di luar tarekat tau pengikut tarekat lain. Amalan khusus ini bisa dilakukan secara individual (fardiyah) maupun secara kolektif (jama'ah). Kedua, ada amalan yang bersifat umum, di mana amalan ini yang menjadi tradisi dalam tarekat, tetapi amalan itu juga bisa dilakukan oleh orang Islam selain pengikut tarekat (Faridy, 2008, p. 1011).

Ajaran Tarekat Idrisiyyah mengambil dari tiga rukun agama yaitu Tauhid, fiqih dan Tasawuf. Tarekat Idrisiyyah mengambil akidah Ahlusunnah wal jamaah, untuk Fiqihnya Tarekat Idrisiyyah mengambil madzhab Imam Syafi'i sebab mayoritas di Indonesia bermadzhab syafi'i akan tetapi ketika Tarekat Idrisiyyah berada di Timur tengah maka 
Jurnal Riset Agama, Volume 1, Nomor 3 (Desember 2021): 276-291

Muhamad Abdul Azis, Yulianti, Muhtar Gojali/Nilai Sufistik Tarekat Idrisiyyah dalam Mengembangkan Karakter Santri

mengambil madzhab Maliki, sedangkan ajaran tasawufnya mengambil dari apa yang diajarkan Syekh Ahmad Ibn Idris begitu juga dengan ulamaulama sufi lainnya. Tarekat Al-Idrisiyyah termasuk dalam jajaran kelompok Tarekat mu'tabaroh dunia dan diakui oleh JATMI (Jam'iyyah Ahli Thariqah Mu'tabarah Indonesia) dan JATMAN (Jam'iyyah Ahlu atThariqah al- Mu'tabarah an-Nahdliyyah). Sebagai bagian dari pergerakan Islam, corak manhaj Tarekat al- Idrisiyyah mengkombinasikan empat macam tarekat: Pertama, Qodiriyyah yang dinisbatkan kepada Syekh Abdul Qodir Jaelani (1078 - 1168 M) dengan keunggulan metode dzikirnya. Kedua, Syadziliyyah yang dinisbatkan kepada Syekh Abu Hasan asy- Syadzili (1197 - $1258 \mathrm{M}$ ) dengan keunggulan konsep zuhudnya sehingga ia terkenal sebagai mursyid yang berdakwah dengan kekayaannya yang melimpah. Ketiga, Al-Idrisiyyah yang dinisbatkan kepada Syekh Ahmad Ibn Idris alFasi (1760 - 1837 M) dengan keunggulan pembaharuan dalam dunia tasawuf. Keempat. Sanusiyyah dinisbatkan kepada Syekh Muhammad ibn Ali as- Sanusi (1787 - $1859 \mathrm{M}$ ) dengan keunggulan pengorganisasiannya yang mengintegrasikan aspek politik, sosial, ekonomi di tengah kehidupan umat sehingga menjadi pergerakan Islam yang diakui dunia Islam dan ditakuti oleh penjajah dari negara-negara Eropa (Faqih, 2021, p. 09.00 WIB).

Nilai sufistik merupakan kata majemuk dari nilai dan sufistik. Menurut Chabib Thoha nilai berarti sifat yang melekat pada kepercayaan yang memberi arti bagi manusia (Sidi, Gazalba, 2002, p. 6). Sufistik sendiri berasal dari kata Ahl Suffah yaitu sekelompok sahabat yang ikut hijrah dengan Nabi Muhammad dari Mekkah ke Madinah dan meninggalkan hartanya di Mekkah. Sehingga dapat ditarik kesimpulan bahwa nilai sufistik merupakan sifat yang melekat pada kepercayaan yang berawal dari Ahl suffah atau seorang sufi (Shihab, 2001, p. 29). Adapun nilai-nilai sufistik yang diterapkan di Tarekat Idrisiyyah antara lain Tazkiyatun Nafs, Tasfiyatul Qalb, Tahdzibul Akhlaq.

a) Tazkiyatun Nafs, secara etimologi Tazkiyatun Nafs mempunyai makna yakni penyucian. Tazkiyatun Nafs adalah upaya membersihkan diri dari maksiat batin yang ada pada hati sehingga seorang hamba bisa lebih dekat dengan Tuhannya (Farid, 2012, p. 13). Tazkiyatun nafs berfungsi untuk membersihkan hati, jiwa dan ruhani. Sebab pada orisinilitasnya ruhani ada dalam keadaan fitrah atau suci yang sifatnya benar-benar butuh kepada Allah. Adapun cara untuk membersihkan hati dari penyakit-penyakit hati yaitu: Pertama, mengetahui jenis penyakit hati, dalam kitab arbain dijelaskan bahwasanya ada sepuluh penyakit hati. Kedua, kesadaran dengan artian dalam membangkitkan kesadaran di bawah bimbingan seorang guru dalam ilmu tasawuf biasa disebut ulama sufi.

b) Tasfiyatul Qalb, secara bahasa dapat diartikan sebagai menghiasi hati dengan cara taat batin.Tasfiyatul qalb juga sering disebut dengan 
Jurnal Riset Agama, Volume 1, Nomor 3 (Desember 2021): 276-291

Muhamad Abdul Azis, Yulianti, Muhtar Gojali/Nilai Sufistik Tarekat Idrisiyyah dalam Mengembangkan Karakter Santri

membangun kualitas hati. Salah satu cara untuk menghiasi hati yaitu dengan perbanyak dzikir, banyak mengingat Allah. Dzikir secara etimologi berasal dari Bahasa Arab yang artinya menyebut atau mengingat. Allah Swt berfirman dalam surat al-Baqarah ayat 152:

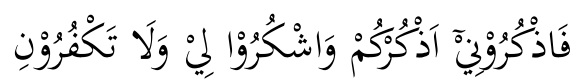

Artinya: "Maka ingatlah kepada-Ku, Aku pun akan ingat kepadamu. Bersyukurlah kepada-Ku, dan janganlah kamu ingkar kepada-Ku."

Dzikir berfungsi membangun komunikasi antara hamba dengan Allah. Pentingnya seorang hamba membangun komunikasi yang intens dengan Allah lewat dzikir sehingga hamba mendapatkan keindahan, kenikmatan dan kebahagiaanya. Ketika hamba menyebut Allah, mengingat Allah, mengagungkan Allah dengan segenap hati maka Allah akan berdzikir kepada hamba-Nya, Allah akan mengingat dan memperhatikan hamba-Nya.

c) Tahdzibul Akhlaq, adalah membangun akhlakul karimah. Tahdzibul Akhlaq adalah terjadinya perubahan budi pekerti atau moral dalam diri sesorang yang dilandasi oleh keyakinan akan pemikiran atau ajaran. Berpijak pada nilai-nilai akhlak, Tahdzibul akhlaq memiliki tujuan untuk membimbing manusia agar tidak terjerumus pada perbuatanperbuatan yang sesat (Alhafidz, 2021, p. 21.57 WIB).

\section{Implementasi Nilai Sufistik Tarekat Idrisiyyah dalam Pengembangan Karakter Satri}

Karakter merupakan cara berpikir dan berperilaku yang mejadi pembeda bagi tiap individu untuk hidup dan bekerjasama baik dalam lingkup keluarga, masyarakat, bangsa dan Negara. Individu yang berkarakter baik adalah individu yang bisa membuat keputusan dan siap mempertanggungjawabkannya (Badrudin, 2015, p. 15). Karakter tidak lepas dengan kondisi sosial budaya, sebab karakter terbentuk dalam lingkungan sosial dan budaya tertentu. Menurut Kamus Besar Bahasa Indonesia karakter diartikan simbol, bawaan, hati, jiwa, budi pekerti, perilaku, personalitas, sifat, tabiat dan watak yang membedakan seseorang dengan yang lain. Karakter mengacu pada attitude, motivation, behavior dan skill. Seseorang dapat dikategorikan berkarakter ketika orang tersebut memiliki kualitas moral, terlihat dari segala tingkah lakunya yang memuat unsur keberanian, kejujuran atau kebiasaan baik (Suwarno, 2017, p. 10).

Menurut Zubaedi dalam bukunya yang berjudul Desain Pendidikan Karakter: Konsep dan Aplikasinya dalam Lembaga Pendidikan, menjelaskan ada empat faktor yang mempengaruhi karakter, di antaranya (Zubaedi, 2011, pp. 177-178): 
Jurnal Riset Agama, Volume 1, Nomor 3 (Desember 2021): 276-291

Muhamad Abdul Azis, Yulianti, Muhtar Gojali/Nilai Sufistik Tarekat Idrisiyyah dalam Mengembangkan Karakter Santri

a) Insting (Naluri), berbagai mode sikap, tindakan, dan tindakan manusia didorong oleh potensi kehendak yang digerakkan oleh naluri. Naluri adalah seperangkat karakteristik yang dimiliki manusia sejak lahir. Insting merupakan kekuatan pendorong yang mendorong lahirnya perilaku. Dengan potensi mengemudi ini, manusia dapat menghasilkan berbagai pola perilaku sesuai dengan pola mengemudinya sendiri.

b) Adat/Kebiasaan, mengacu pada setiap perilaku atau perilaku yang dilakukan berulang-ulang dalam bentuk yang sama untuk dijadikan kebiasaan, seperti berpakaian, makan, tidur, dan berolahraga. Dalam perkembangan selanjutnya, suatu tindakan yang dilakukan berulang kali dan telah menjadi kebiasaan diselesaikan dalam waktu singkat dengan waktu dan perhatian yang sangat sedikit.

c) Keturunan, secara langsung maupun tidak langsung sangat berpengaruh terhadap pembentukan watak atau sikap seseorang. Sifatsifat anak cerminan dari orang tua. Meskipun peran hereditas tidak mutlak, tetapi dikenal di setiap suku, negara, dan wilayah.

d) Lingkungan, salah satu aspek yang mempengaruhi sikap dan perilaku seseorang adalah faktor lingkungan dimana seseorang berada. Ada dua jenis lingkungan, yaitu lingkungan alam dan lingkungan sosial. Lingkungan alam dapat mengganggu atau mematangkan kemampuan seseorang untuk berkembang. Lingkungan sosial saling mempengaruhi dalam hal pemikiran, sifat, dan perilaku.

Kebutuhan spiritual di era modern yang penuh tantangan saat ini amat dibutuhkan bagi siapapun, banyak hal menuntut kemampuan seseseorang dalam mengelola potensi manusia berupa jiwa/ruhani. Sufi Training Center merupakan lembaga otonom yang dibentuk oleh pengurus di Tarekat Idrisiyyah Tasikmalaya. Training STC menggunakan konsep 3T (Tazkiyatun Nafs, TashfiyatulQalb dan Tahzibul Akhlaq) adalah sebuah metode training yang mampu menggabungkan tiga potensi dasar manusia, yaitu kecerdasan intelektual (IQ), kecerdasan emosional (EQ), dan kecerdasan spiritual (SQ) sehingga memberikan motivasi intelektual, emosional, dan spiritual dalam upaya meraih kebahagiaan hakiki. Dalam kaitannya dengan upaya internalisasi misi, visi, dan nilai, STC mampu menjadikan ketiga hal itu menjadi sebuah keyakinan pribadi (personal beliefs) (Hidayatullah, 2021, p. 14.44 WIB).

Pondok Pesantren Idrisiyyah sebagai Pondok Pesantren berbasis tasawuf sudah pasti segala sesuatu yang dilakukan santri tidak akan keluar dari tiga nilai sufistik tarekat Idrisiyyah. Tarekat Idrisyyah sendiri mengambil paham tasawuf amali. Tasawuf amali lebih menekankan pembinaan moral dalam upaya mendekatkan diri kepada Tuhan. Untuk mencapai hubungan yang dekat dengan Tuhan, seseorang harus mentaati dan melaksanakan syariat atau ketentuan agama, menghapuskan segala 
Jurnal Riset Agama, Volume 1, Nomor 3 (Desember 2021): 276-291

Muhamad Abdul Azis, Yulianti, Muhtar Gojali/Nilai Sufistik Tarekat Idrisiyyah dalam Mengembangkan Karakter Santri

sifat yang tercela, melintasi semua hambatan itu dan menghadap total dari segenap esensi diri hanya kepada Allah swt dengan berbagai wirid dan amaliah-amaliah lainnya (Muhtar Sholihin, Rosihon Anwar;, 2014, p. 18).

Salah satu cara yang paling efektif dilakukan oleh Pondok pesantren Idrisiyyah adalah dengan bimbingan seorang Mursyid sehingga selama 24 jam santri Idrisiyyah selalu dibersihkan hatinya, dihiasi hatinya, belajar untuk menjadi pribadi yang lebih baik. Adapun cara lain di tarekat Idrisiyyah ini dalam menerapkannya dengan cara awrad wajib di setiap harinya, dzikir makhsus setiap malam jum'at, setiap bulannya dengan pengajian Arbain, setiap tahunnya melalui kegiatan Qini Nasional. Sehingga tumbuh pribadi santri yang berakhlakul karimah, akhlak yang baik (Comara, 2021, p. 16.30 WIB).

Dalam upaya pendidikan karakter pada santri tarekat Idrisiyyah melakukan formulasi dengan adanya Sufi Training Center sebagai lembaga pelatihan untuk meningkatkan kualitas santri dalam memahami nilai sufistik di Pondok Pesantren Idrisiyyah. Adapun jadwal harian santri di Pondok Pesantren Idrisiyyah sebagai berikut (Hidayatullah, 2021, p. 14.44 WIB):

Tabel. 2 Kegiatan Harian Santri

\begin{tabular}{|c|c|c|c|}
\hline \multicolumn{4}{|c|}{ Kegiatan Harian } \\
\hline No & Waktu & Nama Kegiatan & Keterangan \\
\hline 1 & $03.45-04.30$ & Sholat Tahajud Berjama'ah & \multirow{3}{*}{ Mesjid Al-Fattah } \\
\hline 2 & $04.30-05.15$ & Shalat Shubuh Berjama'ah & \\
\hline 3 & $05.15-06.00$ & KBM Pagi dan Isyrok Berjama'ah & \\
\hline 4 & $06.00-07.15$ & Preparing & \multirow{2}{*}{ Lingkungan Asrama } \\
\hline 5 & $07.15-07.30$ & Muhadatsah & \\
\hline 6 & $07.30-09.50$ & KBM Siang & Sekolah \\
\hline 7 & $09.50-10.10$ & Istirahat Pertama & Lingkungan Asrama \\
\hline 8 & $10.10-11.20$ & KBM Siang & Sekolah \\
\hline 9 & $11.20-13.15$ & $\begin{array}{l}\text { Istirahat Kedua dan Sholat Dzuhur } \\
\text { Berjama'ah }\end{array}$ & Lingkungan Asrama \\
\hline 10 & $13.15-15.00$ & KBM Siang & Sekolah \\
\hline 11 & $15.00-16.00$ & $\begin{array}{l}\text { Selesai KBM dan Sholat Ashar } \\
\text { Berjama'ah }\end{array}$ & \multirow{3}{*}{ Lingkungan Asrama } \\
\hline 12 & $16.00-17.00$ & Ekskul Akademik dan Non Akademik & \\
\hline 13 & $17.00-17.30$ & Free Time & \\
\hline 14 & $17.30-17.50$ & Tadarus & \multirow{2}{*}{ Mesjid Al-Fattah } \\
\hline 15 & $17.50-18.30$ & Sholat Maghrib Berjama'ah & \\
\hline 16 & $18.00-19.00$ & Makan Malam & Lingkungan Asrama \\
\hline 17 & $19.00-19.30$ & Shalat Isya Berjama'ah & Mesjid Al-Fattah \\
\hline 18 & $19.30-21.00$ & Belajar Malam & Lingkungan Asrama \\
\hline
\end{tabular}


Jurnal Riset Agama, Volume 1, Nomor 3 (Desember 2021): 276-291

Muhamad Abdul Azis, Yulianti, Muhtar Gojali/Nilai Sufistik Tarekat Idrisiyyah dalam Mengembangkan Karakter Santri

$19 \quad 21.00-03.30 \quad$ Tidur Malam Kamar Santri

Banyak hal menuntut kemampuan manusia dalam mengelola potensi berupa jiwa/ruhani. Menghadapi persoalan menuntut ilmu dan lainnya adalah Sebagian dari problematika yang sering dihadapi. Permasalahan kehidupam tidak pernah berakhir selama nafas mengalir dalam tubuh begitu pula dengan yang dihadapi oleh santri di Pondok Pesantren Tarekat Idrisiyyah. Tabel di atas merupakan kegiatan harian yang diterapkan oleh pengurus Pondok Pesantren Tarekat Idrisiyyah untuk mengorganisir aktivitas santri dalam kesehariannya dari mulai bangun tidur sampai tidur kembali. Setiap aktivitas santri dipantau langsung oleh wali murid sebagai bentuk mapping kepada santri dengan tujuan wali murid dapat mengarahkan santri yang mapping agar dapat mengembangkan kualitas diri sesuai dengan kemampuannya sehingga dalam pembentukan karakter santri dapat lebih mudah karena wali murid lebih tahu apa yang menjadi kelebihan ataupun kekurangan dari setiap santri.

\section{Kesimpulan}

Berdasarkan hasil penelitian dapat ditarik kesimpulan bahwa tarekat merupakan suatu jalan yang ditempuh oleh seorang sufi dengan tujuan untuk mendekatkan diri kepada Allah Swt. Untuk mencapai tujuan tersebut seorang salik dapat melakukan beberapa metode agar tujuannya tercapai yaitu mencapai cinta ilahi. Pada tarekat Idrisiyah metode atau ikhtiar-ikhtiar yang dilakukan di antaranya ialah dengan melakukan ibadah-ibadah lahiriyah dengan mengacu kepada madzhab Imam Syafi'i, serta mengambil ajaran tasawuf yang dibawa oleh Syekh Ahmad Ibnu Idris dimana ajaran tarekatnya mengarah kepada tiga rukun agama yaitu tauhid, fiqih dan tasawuf. Dalam sebuah tarekat memiliki nilai sufistiknya masingmasing, dalam hal nilai sufistik dalam tarekat Idrisiyah di antaranya ada tazkiyatun nafs (penyucian jiwa), tasfiyatul qalb (penghiasan hati), dan tahdzibul akhlak (membangun akhlakul karimah).

Pondok Pesantren Idrisiyyah merupakan pesantren yang berbasis tasawuf yang lebih menekankan kepada pembinaan moral untuk mengembangkan karakter santri dalam upaya mendekatkan diri kepada Allah. Metode yang digunakan untuk mengembangkan karakter santri serta upaya untuk tetap menjaga nilai sufistik dari tarekat Idsiriyyah adalah dengan adanya bimbingan dari seorang mursyid secara intens dengan menerapkan secara rutin bacaan awrod, dzikir makhsus, serta pengajian Arbain yang diadakan setiap tahun, agar para santri selalu senantiasa menjaga hatinya untuk tetap mengingat Allah sehingga dapat menjadi pribadi yang lebih baik. Upaya lain yang dilakukan yaitu dengan adanya Sufi Training Center yang merupakan lembaga otonom yang dibentuk oleh pengurus di Pondok Pesantren Idrisiyyah. STC ini menekankan kepada 
Jurnal Riset Agama, Volume 1, Nomor 3 (Desember 2021): 276-291

Muhamad Abdul Azis, Yulianti, Muhtar Gojali/Nilai Sufistik Tarekat Idrisiyyah dalam Mengembangkan Karakter Santri

konsep 3T (Tazkiyatun nafs, Tasyfiyatul qalb, da Tahzibul akhlaq) dimana ketiga ini merupakan nilai sufistik dari ajaran Tarekat Idrisiyah.

Diharapkan penelitian ini dapat dijadikan sumber ilmu pengetahuan serta dapat menjadi rujukan pada penelitian yang akan datang khususnya di Jurusan Tasawuf Psikoterapi, serta dapat menjadi tambahan informasi untuk mengembangkan penelitian ini lebih lanjut dan meyakinkan bahwa nilai sufistik dari tarekat manapun dapat bermanfaat bagi kehidupan sehari-hari. Peneliti menyadari dalam penulisan maupun proses pengolahan data masih terdapat kekurangan atau keterbatasan seperti informasi yang didapat belum sepenuhnya komprehensif dan akurat.

\section{Daftar Pustaka}

Alhafidz, R. (2021, Juli Rabu). Pengajar di Pondok Tarekat Idrisiyyah. 21.57. (M. a. Azis, Interviewer) Tasikmalaya.

Badrudin, D. H. (2015). Akhlak Tasawuf. Serang: IAIB Press.

Bagir, H. (2019). Mengenal Tasawuf Spiritualisme Dalam Islam. Jakarta: Noura Books.

Bagir, H. (2019). Mengenal Tasawuf Spiritualisme Dalam Islam. Jakarta: Noura Books.

Cahyono, S. (2019). kabur dari ponpes, seorang santri tewas. Jawa Pos.

Comara, A. (2021, Juli Kamis). Santri di Pondok Pesantren Tarekat Idrisiyyah. 16.30. (M. A. Azis, Interviewer) Tasikmalaya.

DR. H. Subaidi. (2015). Sufisme dan Pengembangan Pendidikan Karakter. Yogyakarta: Kaukaba Dipantara.

Faqih, A. (2021, Juli Jum'at). Ketua Majelis Ketarekatan Idrisiyyah. 09.00 WIB. (M. a. Azis, Interviewer)

Farid, S. A. (2012). Tazkiyatun An-Nafs Mensucikan Jiwa. Sukoharjo: Grokol.

Faridy, H. M. (2008). Enklopedia Tasawuf. Bandung: Angkasa.

Fauzi, R. (2021, Juli Jum'at). Kepala Direktorat Ma'had Aly. 14.23. (M. A. Azis, Interviewer) Tasikmalaya.

Gojali, M. (2019). Psikologi Tasawuf. Bandung: Fakultas Ushuluddin UIN Sunan Gunung Djati.

Hidayatullah, D. (2021, Juli Jum'at). Ketua Divisi Sufi Training Center. 16.00 WIB. (M. A. Azis, Interviewer) Tasikmalaya.

Junaidin. (2019). Tantangan Zaman Terhadap Eksistensi Nilai Raso (bersuci) Dalam Pendidikan Aakhlak Tasaawuf Pada Masyarakat Ntori Bima. JUrnal Study Pendidikan Islam, 28.

Kamba, N. (2013). Naskah Akademik Gelar Sarjana Jurusan Tasawuf Psikoterapi. Bandung: Fakultas Ushuluddin UIN Sunan Gunung Djati Bandung.

Kamba, N. (2018). Kids Zaman Now Menemukan Kembali Islam. Tangerang selatan: Pustaka Iman.

Kamba, N. (2018). Kids Zaman Now Menemukan Kembali Islam. Tangerang selatan: Pustaka Iman. 
Jurnal Riset Agama, Volume 1, Nomor 3 (Desember 2021): 276-291

Muhamad Abdul Azis, Yulianti, Muhtar Gojali/Nilai Sufistik Tarekat Idrisiyyah

dalam Mengembangkan Karakter Santri

Kependidikan, D. (2008). Pendekatan, Jenis dan Metode Penelitian dan Pendidikan. Jakarta: Dirjen PMPTK.

Moleong. (2009). Metode Penelitian Kualitatif Edisi Revisi. Bandung: Remaja Rosdakarya.

Muhammad Baidhawi. (2016). Aplikasi Nilai-Nilai Sufistik Terhadap Mahasiswa Tasawuf Psikoterapi Dalam Kehidupan Modern. Bandung: UIN Sunan Gunung Djati.

Muhtar Sholihin, Rosihon Anwar;. (2014). Ilmu Tasawuf. Bandung: Pustaka setia.

Nasaruddin, U. (2014). Tasawuf Modern. Jakarta: Republika.

Pupuh Fathurrohman, A. S. (2013). Pengembangan Pendidikan Karakter. Bandung: Refika Aditama.

Rusmaini. (1999). Nilai-Nilai Sufistik Dalam Karya-Karya Emha Ainun Najib. Lampung: Fakultas Ushuluddin IAIN Raden Intan Lampung.

Shihab, A. (2001). Islam Sufistik. Bandung: Mizan.

Sidi, Gazalba. (2002). Sistematika Filsafat: Pengantar Kepada Teori Nilai. Jakarta: Bulan Bintang.

Sukmadinata, N. S. (2009). Metode Penelitian Pendidika. Bandung: Remaja Rosdakarya.

Suwarno. (2017). Pondok Pesantren dan Pembentukan Karakter. OASIS: Jurnal Ilmiah Kajian Ilam, 10.

Syamsuddin. (2007). Metodologi Penelitian Living Quran dan Hadist. Yogyakarta: TH Press.

Wan Saleha Wan Sayed, M. H. (2020). Institusi Tarekat Tasawuf Dalam Pemantapan Spiritual Insan. Malaysian For Islamic Studies, 66.

Zubaedi. (2011). Desain Pendidikan Karakter: Konsep dan Aplikasinya dalamLembaga Pendidikan. Jakarta: Kencana.

Zubaedi. (2012). Desain Pendidikan Karakter. Jakarta: Kencana Prenada Media Group. 